\title{
A Importância da Triagem Neonatal para a Detecção Precoce da Anemia Falciforme
}

\author{
The Importance of Neonatal Screening for the Early Detection of Sickle Cell Anemia \\ La Importancia del Cribado Neonatal para la Detección Precoz de la Anemia Falciforme
}

Recebido: 24/06/2021 | Revisado: 30/06/2021 | Aceito: 01/07/2021 | Publicado: 14/07/2021

Carolina Dias Reis

ORCID: https://orcid.org/0000-0002-4916-4183

Escola Superior da Amazônia, Brasil

E-mail: carolina17sud@gmail.com

Maisa de Lima Barbosa

ORCID: https://orcid.org/0000-0001-6096-4862 Escola Superior da Amazônia, Brasil E-mail: maisalima508@gmail.com

Manoele Sousa Araújo

ORCID: https://orcid.org/0000-0002-4342-735X Escola Superior da Amazônia, Brasil E-mail: manoeledearaujo@gmail.com

Murilo Tavares Amorim

ORCID: https://orcid.org/0000-0002-9769-2183 Universidade Federal do Pará, Brasil

E-mail: muriloamorimbio@gmail.com

Michele Amaral da Silveira

ORCID: https://orcid.org/0000-0001-5119-7526 Escola Superior da Amazônia, Brasil E-mail: mi_biom@yahoo.com.br

\begin{abstract}
Resumo
Anemia falciforme é uma doença genética, transmitida por uma herança autossômica recessiva, representada pela existência de eritrócitos em forma de foice, e de grande prevalência no Brasil. Os portadores dessa patologia são assintomáticos nos primeiros seis meses de vida. O diagnóstico precoce dá-se através da triagem neonatal, permitindo o acompanhamento dos pacientes antes das manifestações e da sintomatologia e, com isto, a prevenção das possíveis sequelas e complicações. Este estudo foi realizado por meio de uma pesquisa bibliográfica qualitativa e quantitativa, tendo como objetivo demonstrar, apontar e correlacionar as principais características dessa patologia com o diagnóstico precoce. Destacando os principais pontos dos artigos relacionados a anemia falciforme e suas complicações, utilizando publicações nacionais e internacionais, das bases de dados: SCIELO (Scientific Electronic Library Online), PubMed, Google Acadêmico e $B V S$, no qual 21 trabalhos fizeram parte da construção dos resultados. Entre esses, 4 foram achados no PubMed, 9 no Sciello,7 no Google Acadêmico e 1 na plataforma BVS. Respondendo aos objetivos descritos, podemos concluir que o diagnóstico precoce é imprescindível, pois o quanto antes a anemia falciforme for detectada, há mais chances da qualidade e expectativa de vida do paciente aumentar, com isso a triagem neonatal tem um papel fundamental para esta detecção.
\end{abstract}

Palavras-chave: Hemoglobina S; Anemia falciforme; Triagem neonatal.

\begin{abstract}
Sickle cell anemia is a genetic disease, transmitted by an autosomal recessive inheritance, represented by the existence of sickle-shaped erythrocytes, and highly prevalent in Brazil. Carriers of this pathology are asymptomatic in the first six months of life. Early diagnosis is achieved through neonatal screening, allowing the monitoring of patients before the manifestations and symptoms and, with this, the prevention of possible sequelae and complications. This study was carried out through a qualitative and quantitative bibliographic research, aiming to demonstrate, point out and correlate the main characteristics of this pathology with early diagnosis. Highlighting the main points of articles related to sickle cell anemia and its complications, using national and international publications, from the databases: SCIELO (Scientific Electronic Library Online), PubMed, Academic Google and VHL, in which 21 works were part of the construction of the results. Among these, 4 were found on PubMed, 9 on Sciello,7 on Google Scholar and 1 on the BVS platform. Responding to the objectives described, we can conclude that early diagnosis is essential, as the sooner sickle cell anemia is detected, there is more chance that the patient's quality and life expectancy will increase, with that the neonatal screening plays a fundamental role in this detection.
\end{abstract}

Keywords: Hemoglobin S; Sickle cell anemia; Neonatal screening.

\section{Resumen}

La anemia drepanocítica es una enfermedad genética, transmitida por herencia autosómica recesiva, representada por la existencia de eritrocitos falciformes, y de alta prevalencia en Brasil. Los portadores de esta patología se encuentran 
asintomáticos en los primeros seis meses de vida. El diagnóstico precoz se logra mediante el cribado neonatal, permitiendo el seguimiento de los pacientes ante de las manifestaciones y síntomas y, con ello, la prevención de posibles secuelas y complicaciones. Este estudio se realizó mediante una investigación bibliográfica cualitativa y cuantitativa, con el objetivo de demostrar, señalar y correlacionar las principales características de esta patología con el diagnóstico precoz. Destacando los principales puntos de los artículos relacionados con la anemia falciforme y sus complicaciones, utilizando publicaciones nacionales e internacionales, de las bases de datos: SCIELO (Scientific Electronic Library Online), PubMed, Academic Google y VHL, en los que 21 trabajos formaron parte de la construcción de los resultados. Entre estos, 4 se encontraron en PubMed, 9 en Sciello, 7 en Google Scholar y 1 en la plataforma BVS. Respondiendo a los objetivos descritos, podemos concluir que el diagnóstico precoz es fundamental, ya que cuanto antes se detecte la anemia falciforme hay más posibilidades de que aumente la calidad y esperanza de vida del paciente, por lo que el cribado neonatal juega un papel fundamental en esta detección.

Palabras clave: Hemoglobina S; Anemia de células falciformes; Cribado neonatal.

\section{Introdução}

A anemia falciforme é uma doença hereditária de grande prevalência no mundo, que produz hemoglobina $\mathrm{Hb} \mathrm{S}$, que seria uma má formação da hemoglobina. A hemoglobina tem como principal função transportar oxigênio dos pulmões para os tecidos, e com a má formação dos eritrócitos que ocorre na anemia falciforme, seu tempo de vida é encurtado drasticamente, afetando de forma grave sua função no corpo e causando diversos sintomas no indivíduo e diminuindo o tempo de vida do paciente. A anemia falciforme tem maior prevalência em negros e pardos, e devido a miscigenação o fator genético espalhou-se no mundo. Sua origem é africana e sua chegada ao Brasil se deu durante a época da escravidão. No Brasil a anemia falciforme é uma doença comum, pois a maior parte da população é negra e parda, por isso é considerada um problema de saúde pública, a Organização Mundial de Saúde (OMS) estima-se que nasçam cerca de 1.900 crianças com anemia falciforme no Brasil (Cavalcante \& Maio, 2011).

Em 1910, a Anemia Falciforme (AF) foi detalhada cientificamente por Jamaes Herrick, que utilizou da microscopia para registrar seus estudos, com o esfregaço sanguíneo de um aluno da América Central. Somente em 1949 o químico Linus Pauling, publicou um artigo que descreve a anemia falciforme como a primeira doença molecular. A hemoglobina $S$ (Hb $S$ ) é a responsável pela AF, foi introduzida no Brasil por tribos africanas que vieram através do tráfico negreiro (Rodrigues et.al.,2012). A doença falciforme teve sua origem na África, através da imigração forçada de escravos, sendo assim introduzida no Brasil. E na região Nordeste, nos estados de São Paulo, Rio de Janeiro e Minas Gerais onde apresenta a maior frequência de afrodescendentes (Levolino et.al., 2011). Anthonny Alisson, observou em 1954, que indivíduos acometidos pelo traço depranocitico improvavelmente eram parasitados por P. falciparum, adquirindo uma seleção seletiva a malária. Associada como uma proteção contra a malária a depranocitose foi uma das primeiras hemoglobinopatias destacadas (Machado et.al., 2010).

Considerada a patologia genética de maior prevalência mundial, a anemia falciforme possui uma frequência de 25 a 40\% em países africanos. A população brasileira apresenta uma composição de mistura de três grupos genéticos, ameríndios, europeus e africanos, sendo estes últimos um conjunto de diversos grupos étnicos. (Soares et.al., 2017). O diagnóstico neonatal de anemia foi implantado no Brasil através da Portaria $n^{\circ}$ 822, do Ministério da Saúde, de 06/06/200. A falta de amparo financeiro, familiar e de políticas públicas podem afetar muito na letalidade dos indivíduos com anemia falciforme, um diagnóstico precoce, atendimento médico eficaz e orientação familiar, seriam ideais para tratamento mais efetivo para esse paciente (Felix et.al., 2010).

"É importante destacar que, no Brasil e em várias regiões do mundo, o grupo étnico acometido, majoritariamente a população negra, está na base da pirâmide social e apresenta os piores indicadores epidemiológicos, educacionais e econômicos" (Rodrigues et.al., 2012).

Segundo a Organização Mundial da Saúde (OMS) as anemias são as doenças que mais atingem a população mundial. 
Na Anemia Falciforme (AF) ocorre uma mutação que causa a alteração de um aminoácido denominado, ácido glutâmico que é substituído pelo aminoácido valina. Essa troca ocorre na posição 6 da cadeia beta, do qual o locus está posicionado no braço curto do cromossomo 11. É uma doença hereditária transmitida a partir de uma herança autossômica recessiva (CRESPO et.al., 2020). Essa mutação acontece pela substituição das bases nitrogenadas, da adenina por timina (GAG-GTG) originando uma hemoglobina anormal, a hemoglobina $\mathrm{S}(\mathrm{Hb} \mathrm{S})$, ao invés de produzir uma hemoglobina normal, que seria a hemoglobina $\mathrm{A}$ ( $\mathrm{Hb}$ A). Com essas modificações as hemácias alteram sua forma normal para formar estrutura denominada de foice, tal evento nomeado como falcização. Com suas características físico-químicas alteradas a hemoglobina $\mathrm{S}$ sofrem polimeração e precipitação, no qual leva a ocorrência da mudança de estrutura da forma dos eritrócitos, tornando-se em forma de foice (drepanócitos) (Levorlino et.al., 2011).

Os programas de triagem neonatal identificam diversas doenças assintomáticas em recém nascidos a tempo de identificar e tratar as sequelas ao seu crescimento, os resultados alterados necessitam de confirmação e tratamento, este percurso envolve várias etapas. (Bother et.al., 2012). "Triagem" significa "separação!, os testes de triagem neonatal não são diagnósticos eles separam a população de recém-nascidos em dois grupos: um constituído por aqueles que podem ter uma doença, e outro por aqueles que não devem ter. Para que se realize a triagem neonatal, é necessário, portanto, que exista um teste adequado com alta sensibilidade (capacidade de identificar corretamente aqueles que têm a doença), e razoável especificidade (capacidade de identificar corretamente aqueles que não têm a doença). (Leão et.al., 2008).

A história da Triagem Neonatal (TN), teve início no Reino Unido no final de 1950, com o rastreio da doença metabólica que era detectável inicialmente através da urina. No começo tratava-se apenas de um projeto pequeno e organizado de detecção de fenilcetonúria com aconselhamento dietético e realizado logo após o nascimento dos recém-nascidos. Em 1960 uma conferência realizada pelo Medical Research Council recomendou as autoridades locais a continuação e a possível expansão do programa de rastreio da fenilcetonúria (Rodrigues et.al., 2012). Assim como ocorreu em outros países desenvolvidos, a inclusão do programa da triagem no Brasil aconteceu de forma desorganizada, sem estrutura alguma, sem organização de controle para obter alguma qualidade e concedeu uma discussão ética em função do assunto. A primeira doença identificada pela triagem foi a fenilcetonúria, que ocorreu após um trabalho pioneiro da APAE/SP (Associação de Pais e Amigos dos Excepcionais de São Paulo), em 1976. Atualmente a TN pode ser realizada em rede privada e pelo Sistema Único de Saúde (SUS) (Souza et.al.,2002).

É de grande significância adicionar a anemia falciforme no grupo de patologias detectadas pela triagem neonatal, pois é uma doença de alta prevalência, principalmente na infância, devido suas complicações. Assim, a triagem neonatal (TN) para a $\mathrm{Hb}$ S, também conhecida como Teste do Pezinho; tem o objetivo de diagnosticar precocemente as doenças falciformes, que habitualmente não apresentam sintomas no período neonatal e assim intervir no seu curso natural (Mendonça et.al., 2009). Portanto é de grande relevância que a doença seja diagnosticada e tratada precocemente, afim de aumentar a expectativa e melhorar a qualidade de vida do paciente.

\section{Metodologia}

Trata-se de uma revisão bibliográfica qualitativa e quantitativa de abordagem explorativa, onde foram utilizadas publicações que abordavam a temática da anemia falciforme. oram utilizadas base de dados das seguintes plataformas, SCIELO (Scientific Electronic Library Online), PubMed e Google Acadêmico, nos idiomas inglês, português e espanhol, onde foram utilizados os seguintes descritores: anemia falciforme, sickel cell diasease, triagem neonatal, hemoglobina $\mathrm{S}$ e teste do pezinho. Os artigos selecionados e incluídos, tiveram como critérios de seleção: artigos publicados no período de 2010 a 2020, artigos publicados em inglês, português e espanhol, artigos disponíveis na integra, artigos com trabalhos experimentais e de revisão. Os selecionados nos critérios de exclusão: trabalhos que não estavam disponíveis na integra, artigos repetidos, artigos com objetivos de estudos que não abordavam aos objetivos propostos (Figura 1). Posteriormente, os resultados foram apresentados com a 
construção de um quadro sinóptico contendo os aspectos de: título do artigo, autores, periódico, ano e síntese, destacando os periódicos que mais publicaram sobre o tema.

Figura 1: Fluxograma da Metodologia.

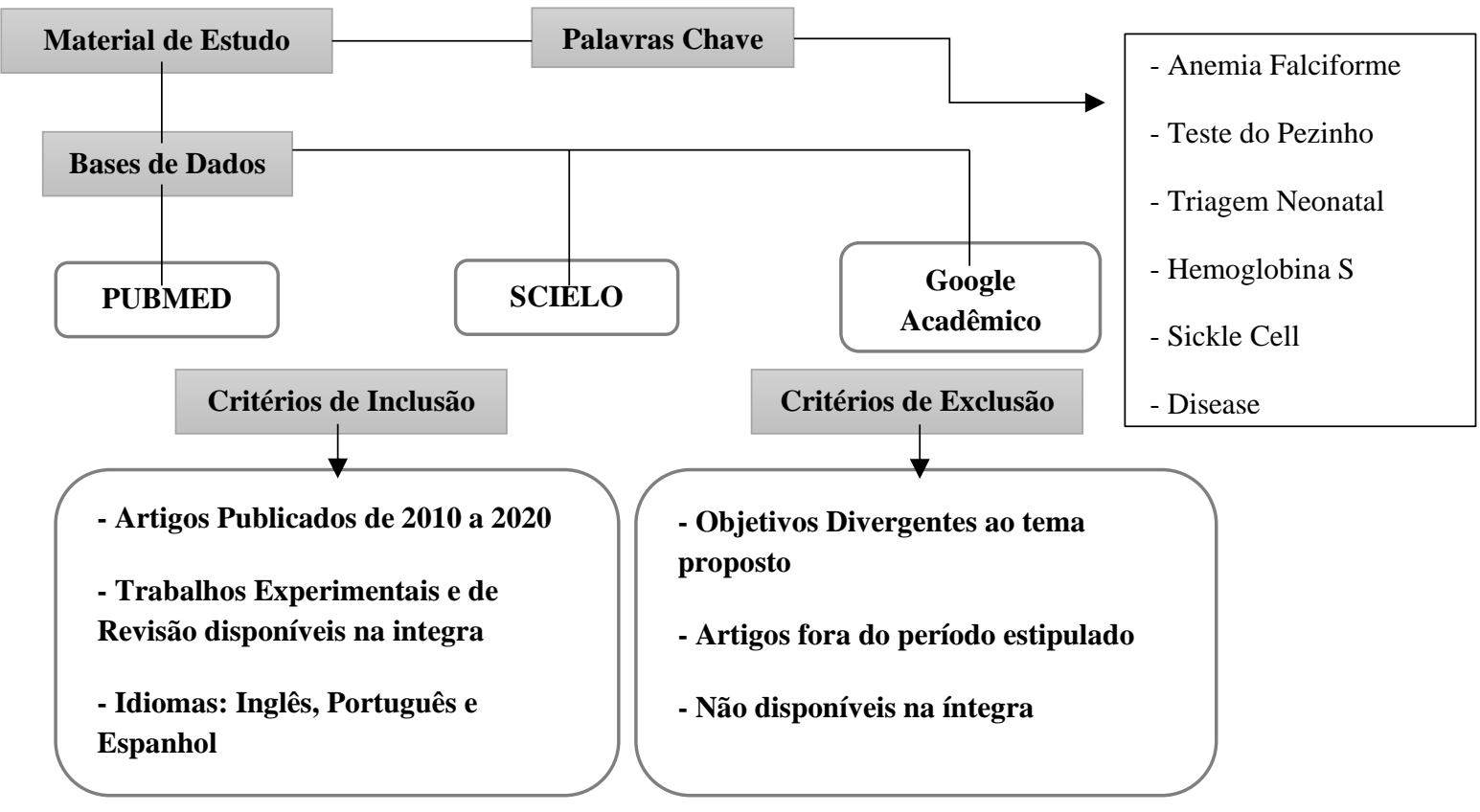

Fonte: Autores (2021).

\section{Resultados}

Empregando as bases de dados significativas e descritas na metodologia. Foram selecionados 65 artigos, no qual 44 enquadravam-se nos critérios de exclusão e 21 nos critérios de inclusão descritos. A figura 2 evidencia a coleta desse material.

Figura 2: Material Selecionado.

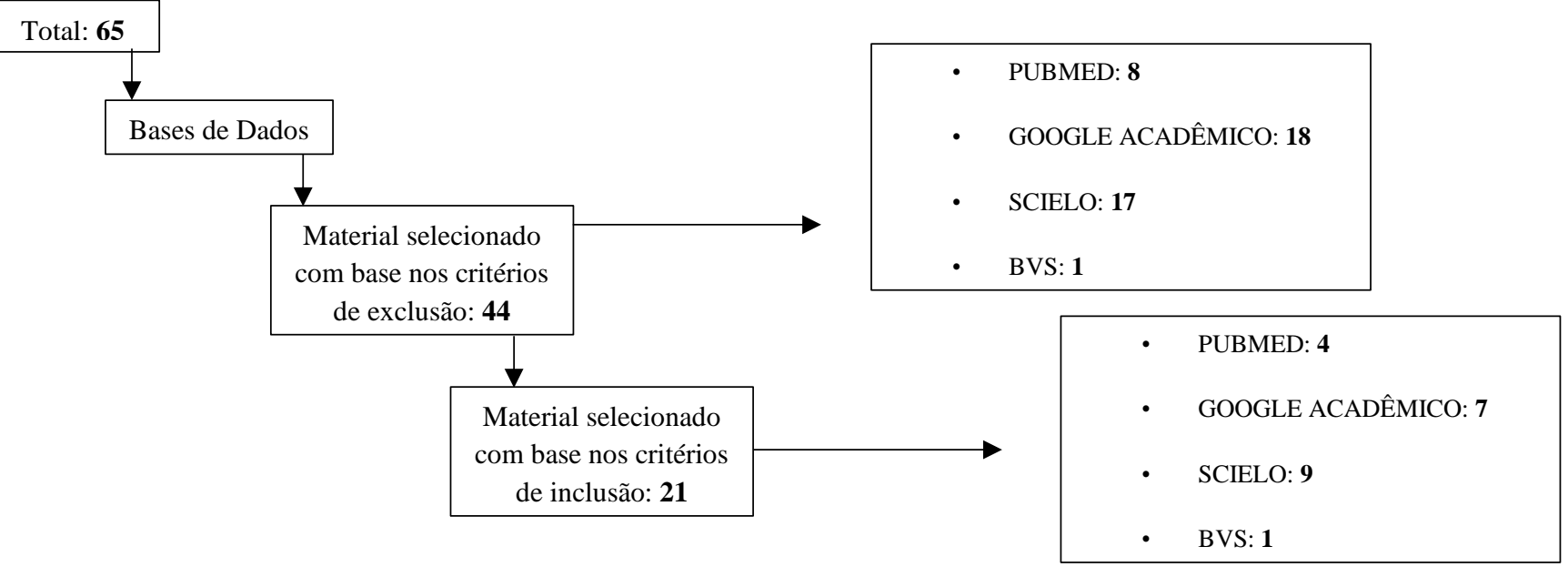

Fonte: Autores (2021).

Os elementos do Quadro 1, demonstram a importância da triagem neonatal para o diagnóstico precoce da anemia falciforme. 
Quadro 1: A importância da Triagem Neonatal para o Diagnóstico Precoce.

\begin{tabular}{|c|c|c|c|c|c|}
\hline & Título do artigo & Autores & Periódicos & Ano & Síntese \\
\hline 1 & $\begin{array}{l}\text { Diagnóstico histórico da triagem } \\
\text { neonatal para doença falciforme }\end{array}$ & $\begin{array}{l}\text { RODRIGUES, D. } \\
\text { O. W.; et. al. }\end{array}$ & Scielo & 2010 & $\begin{array}{l}\text { Este artigo apresenta a evolução histórica do processo de } \\
\text { criação e implementação da triagem neonatal no Brasil e } \\
\text { em partes do mundo }\end{array}$ \\
\hline 2 & $\begin{array}{l}\text { Morbimortalidade em doença } \\
\text { falciforme }\end{array}$ & $\begin{array}{l}\text { MARTINS, J. R. } \\
\text { P.; et. al. }\end{array}$ & Scielo & 2010 & $\begin{array}{l}\text { A alta morbimortalidade referida na doença falciforme } \\
\text { (DF) levou-nos a estudar o perfil epidemiológico e } \\
\text { respectivas intercorrências clínicas dos pacientes }\end{array}$ \\
\hline 3 & $\begin{array}{l}\text { História da triagem neonatal para } \\
\text { doença falciforme no Brasil: capítulo } \\
\text { de Minas Gerais }\end{array}$ & $\begin{array}{l}\text { RODRIGUES, D. } \\
\text { O. W.; et. al. }\end{array}$ & BVS & 2012 & $\begin{array}{l}\text { Este artigo apresenta a evolução histórica do processo de } \\
\text { criação e implementação da triagem neonatal no Brasil }\end{array}$ \\
\hline 4 & $\begin{array}{l}\text { Anemia falciforme: um problema de } \\
\text { saúde pública, o papel da triagem } \\
\text { neonatal no diagnóstico e } \\
\text { acompanhamento terapêutico }\end{array}$ & $\begin{array}{l}\text { BESSONI, T.; et. } \\
\text { al. }\end{array}$ & $\begin{array}{l}\text { Google } \\
\text { Acadêmico }\end{array}$ & 2014 & $\begin{array}{l}\text { Neste estudo são apresentadas as características e } \\
\text { manifestações clínicas da doença, diagnóstico feito pela } \\
\text { triagem neonatal e tratamentos }\end{array}$ \\
\hline 5 & $\begin{array}{l}\text { Doença falciforme e triagem neonatal: } \\
\text { Um debate necessário }\end{array}$ & $\begin{array}{l}\text { DE SOUZA, M. I; } \\
\text { A; et. al. }\end{array}$ & $\begin{array}{l}\text { Google } \\
\text { Acadêmico }\end{array}$ & 2016 & $\begin{array}{l}\text { Este artigo objetiva discutir os aspectos clínicos e } \\
\text { epidemiológicos relacionados à doença falciforme, assim } \\
\text { como a fundamentação da triagem neonatal nesse cenário }\end{array}$ \\
\hline 6 & $\begin{array}{l}\text { A importância da triagem neonatal para } \\
\text { o diagnóstico da anemia falciforme }\end{array}$ & $\begin{array}{l}\text { OLIVEIRA, P. } \\
\text { K.; et. al. }\end{array}$ & $\begin{array}{l}\text { Google } \\
\text { acadêmico }\end{array}$ & 2020 & $\begin{array}{l}\text { O trabalho tem como objetivo reconhecer a importância do } \\
\text { teste do pezinho (TP) no Brasil para o diagnóstico precoce } \\
\text { e tratamento da AF para oferecer melhor qualidade de vida } \\
\text { para os pacientes e melhorar a sobrevida. }\end{array}$ \\
\hline
\end{tabular}

Fonte: Autores (2021).

Os estudos analisados no Quadro 2, visam apontar as principais características da anemia falciforme para o diagnóstico precoce.

Quadro 2: As principais características da anemia falciforme para o diagnóstico precoce.

\begin{tabular}{|c|c|c|c|c|c|}
\hline & Título do artigo & Autores & Periódicos & Ano & Síntese \\
\hline 1 & $\begin{array}{l}\text { Mortalidade de crianças com } \\
\text { doença falciforme: um estudo de } \\
\text { base populacional }\end{array}$ & $\begin{array}{l}\text { FERNANDES, } \\
\text { C. P.; et. al. }\end{array}$ & Scielo & 2010 & $\begin{array}{l}\text { Caracterizar os óbitos das crianças com doença falciforme (DF) } \\
\text { triadas no estado de Minas Gerais e acompanhadas na Fundação } \\
\text { Hemominas }\end{array}$ \\
\hline 2 & $\begin{array}{l}\text { Hematology clinic.Sickle cell } \\
\text { disease }\end{array}$ & $\begin{array}{l}\text { NUGO, D.; et. } \\
\text { al. }\end{array}$ & PubMed & 2014 & $\begin{array}{l}\text { As células falciformes rígidas e anormais obstruem pequenos } \\
\text { vasos sanguíneos e o fornecimento de oxigênio, causando danos } \\
\text { progressivos aos órgãos }\end{array}$ \\
\hline 3 & $\begin{array}{l}\text { A importância do diagnóstico } \\
\text { precoce da anemia falciforme }\end{array}$ & $\begin{array}{l}\text { MAIA, A. O.; et. } \\
\text { al. }\end{array}$ & $\begin{array}{l}\text { Google } \\
\text { Academico }\end{array}$ & 2017 & $\begin{array}{l}\text { O diagnótico precoce, permite uma melhor qualidade de vida aos } \\
\text { portadores. }\end{array}$ \\
\hline 4 & Sickle cell disease & $\begin{array}{l}\text { PIEL, F. B.; et. } \\
\text { al. }\end{array}$ & PubMed & 2017 & $\begin{array}{l}\text { A doença falciforme é um problema de saúde global. O } \\
\text { diagnóstico precoce, pode melhorar a sobrevivência e qualidade } \\
\text { de vida dos pacientes. }\end{array}$ \\
\hline 6 & $\begin{array}{l}\text { Inflammation in Sickle Cell } \\
\text { Disease }\end{array}$ & $\begin{array}{l}\text { CONRAN, N.; } \\
\text { et. al. }\end{array}$ & PubMed & 2019 & $\begin{array}{l}\text { A mutação do gene } \beta \text {.globina tem consequências fisiopatológicas } \\
\text { que resultam em eventos hemolíticos. }\end{array}$ \\
\hline 7 & $\begin{array}{l}\text { Importancia de la detección } \\
\text { temprana de hemoglobinopatias } \\
\text { en la población pediátrica en } \\
\text { países en desarrollo }\end{array}$ & $\begin{array}{l}\text { AGUIRRE, M.; } \\
\text { et.al. }\end{array}$ & Scielo & 2020 & $\begin{array}{l}\text { Alertar o pessoal de saúde para a importância da detecção } \\
\text { precoce das hemoglobinopatias, por ser o distúrbio monogênico } \\
\text { recessivo mais comum. }\end{array}$ \\
\hline
\end{tabular}


No Quadro 3 estão listados os estudos que correspondem a correlação do diagnóstico precoce com a melhora da qualidade de vida do paciente.

Quadro 3: Diagnóstico precoce para melhora da qualidade de vida do paciente.

\begin{tabular}{|c|c|c|c|c|c|}
\hline & Título do artigo & Autores & Periódico & Ano & Síntese \\
\hline 1 & $\begin{array}{l}\text { Informação genética na mídia } \\
\text { impressa: a anemia falciforme } \\
\text { em questão. }\end{array}$ & DINIZ, D.; et.al. & Scielo & 2010 & $\begin{array}{l}\text { As análises das matérias identificaram um forte apelo } \\
\text { preventivo que acompanha anemia facilforme. }\end{array}$ \\
\hline 2 & Doença falciforme no Brasil & JESUS, J. A. & $\begin{array}{l}\text { Google } \\
\text { Acadêmico }\end{array}$ & 2010 & A causa dessa doença de herança recessiva \\
\hline 3 & $\begin{array}{l}\text { Qualidade de vida em } \\
\text { portadores de doença falciforme }\end{array}$ & MENEZES, A., et. al. & Scielo & 2013 & $\begin{array}{l}\text { O primeiro passo rumo à construção de tal programa } \\
\text { foi dado com institucionalização da triagem neonatal } \\
\text { no SUS }\end{array}$ \\
\hline 4 & $\begin{array}{l}\text { Principais técnicas para o } \\
\text { diagnóstico da anemia } \\
\text { falciforme: uma revisão de } \\
\text { literatura }\end{array}$ & SILVA, N. C. H. & Scielo & 2017 & $\begin{array}{l}\text { A anemia falciforme é uma doença de caráter genético } \\
\text { ocasionada pela mutação no cromossomo } 11 \text {. }\end{array}$ \\
\hline 5 & $\begin{array}{l}\text { Doença Falciforme e o teste do } \\
\text { pezinho :implicações para a } \\
\text { saúde pública }\end{array}$ & $\begin{array}{l}\text { BRUZEGUINE, V. M.; et. } \\
\text { al. }\end{array}$ & $\begin{array}{l}\text { Google } \\
\text { Acadêmico }\end{array}$ & 2018 & $\begin{array}{l}\text { O teste é uma ação preventiva que permite } \\
\text { diagnosticar doenças geneticamente infecciosas. }\end{array}$ \\
\hline 6 & $\begin{array}{l}\text { Qualidade de vida dos } \\
\text { portadores de doença falciforme }\end{array}$ & LIMA, K. T. L. L. et. al. & $\begin{array}{l}\text { Google } \\
\text { Acadêmico }\end{array}$ & 2019 & $\begin{array}{l}\text { Avaliar a qualidade de vida dos portadores de células } \\
\text { falciformes }\end{array}$ \\
\hline 7 & $\begin{array}{l}\text { A participação dos conviventes } \\
\text { com a doença falciforme na } \\
\text { atenção à saúde:um estudo } \\
\text { bibliográfico }\end{array}$ & LOPES, W. S. L.; et. al. & Scielo & 2020 & $\begin{array}{l}\text { Analisar a produção científica publicada acerca da } \\
\text { participação dos sujeitos da doença falciforme (DF) e } \\
\text { seus familiares, bem como sobre a autonomia e os } \\
\text { aspectos sociais relacionados a esses sujeitos. }\end{array}$ \\
\hline 8 & $\begin{array}{l}\text { Condições clinicas, nutricionais } \\
\text { e sociais de crianças com } \\
\text { doença falciforme } \\
\text { acompanhadas em um centro de } \\
\text { referências: estudo descritivo }\end{array}$ & SANTOS, I. N.; et.al. & Scielo & 2020 & $\begin{array}{l}\text { Características sociais e nutricionais de crianças com } \\
\text { anemia falciforme de 5-9 anos. }\end{array}$ \\
\hline
\end{tabular}

Fonte: Autores (2021).

\section{Discussão}

Os autores que responderam ao primeiro objetivo foram: Rodrigues, et.al., (2010) diz a triagem de hemoglobinopatias é uma análise importante para a prevenção das doenças falcêmicas. Rodrigues et.al., (2012), em um trabalho mais atual diz, o "teste do pezinho" é uma estratégia para o diagnóstico precoce de algumas doenças congênitas que são, em sua maioria, imperceptíveis ao exame médico no período neonatal e Benossi et.al., (2014) e também afirma que os métodos de triagem apresentam alto grau de sensibilidade e especificidade, também reduzem a taxa de mortalidade nos primeiros cinco anos de vida. Souza et.al., (2016) diz que a inclusão das hemoglobinopatias no Programa Nacional de Triagem Neonatal, através da Portaria $n^{\circ}$ 822, representou um importante avanço no reconhecimento das hemoglobinopatias em saúde pública no Brasil. Oliveira, et.al., (2020) concorda e diz como é importante o diagnóstico precoce através da triagem neonatal, pois permite o tratamento do paciente, aumentando a sobrevida e abordando de forma correta o aconselhamento genético quando essa criança se tornar adulto.

Os autores que responderam ao segundo objetivo foram: Zúñiga et.al., (2018), diz que portadores homozigotos são caracterizados como Hb SS e representam cerca de 60-65\% dos pacientes sintomáticos. Nugo e Steinberg (2014), citam em seu artigo que os portadores dessa doença já nascem com ela, podendo ou não desenvolver complicações de anemia e lesões a órgãos do corpo a partir da infância. Fernandes et.al., (2010), demonstra em sua publicação que as principais determinantes das indicações clinicas da doença falciforme são: os fenômenos de vaso-oclusivos e a hemólise crônica. Caracterizando-se como 
uma doença sistêmica que pode acometer quaisquer órgãos, porém, a alteração predominante estar restringida aos eritrócitos sanguíneos. Já para Conran e Belcher (2019), afirmam que além dos episódios de vaso-oclusão que tem como principal característica da DF, o principal componente para as complicações da doença, que inclui a Síndrome Torácica Aguda, úlceras nas pernas, nefropatia e derrame, são os processos inflamatórios.

As estimativas de Piel et.al., (2017) sugeriram que cerca de 300.00 bebês nasçam portadores da doença falciforme a cada ano, e que até 2050 esse número poderá expandir para 400.00. Segundo Maia et.al., (2017), afirma em seu trabalho que o quanto mais precocemente for realizado o diagnóstico para anemia falciforme, mais rapidamente poderá ser desenvolvida medidas que tendem diminuir a morbimortalidade entre esses portadores, em concordância, Marisol et.al., (2020), afirma que o diagnóstico tardio implica na má qualidade de vida e consequentemente no aumento dos sintomas e crises dolorosas.

Os autores que responderam ao terceiro objetivo foram: Jesus (2010) diz e Lopes e Gomes, (2020) concordam que no Brasil, o diagnóstico precoce é realizado na primeira semana de vida do paciente, e é feito nos estados, pelos serviços de referência em triagem neonatal. Segundo Santos et.al., (2020) apesar do diagnóstico e acompanhamento precoce das crianças com DF, verificou-se que elas permanecem em vulnerabilidade clínica com o avanço da idade, pois apresentam intercorrências clínicas graves. Segundo Menezes, et.al., (2013) a doença crônica na infância utiliza-se de cuidados e de uma participação mais especifica dos pais, e nas adequações com as novas situações ao longo do período de crescimento, mesmo para indivíduo saudável ocorrerá a modificação em sua saúde e bem-estar.

Para Diniz et.al., (2010), a vantagem da detecção precoce como mecanismo para reduzir a prevalência da doença é de conhecimento comum na comunidade científica, pois além de mapear melhor a doença no país, a intervenção imediata também afetará as expectativas e a qualidade de vida da população. Silva et.al., (2017) diz que em geral, é possível identificar que a anemia falciforme tem grande relevância na visão. Entretanto, Bruzeguini (2018), afirma que a diminuição da taxa de mortalidade infantil é provável no momento que tem um conhecimento melhor do cenário epidemiológico. Lima et.al., (2019) nos dias de hoje é possível a cura ao ser realizado um TMO, porém é um processo agressivo podendo comprometer diversos órgãos e causar depressão imunológica, e a questão sobre qualidade de vida que irá surgir diante desta situação.

\section{Considerações Finais}

O diagnóstico precoce é de grande relevância para essa patologia, que o quanto mais tardiamente a criança for diagnosticada, maior será os agravos das manifestações clinicas em decorrência da AF, dessa forma acarretando na diminuição da qualidade de vida desses portadores. A anemia falciforme quando detectada nos primeiros dias de vida, e com tratamento apropriado reduz as crises da doença, também diminuindo a taxa de mortalidade aumentando a expectativa de vida do paciente. Outro fator importante é a condição socioeconômica, que como visto na literatura pode influenciar no tratamento e expectativa de vida, e como uma proposta para órgãos públicos, ressaltamos a importância do amparo financeiro(auxílios) e a educação familiar em relação ao tratamento do paciente com AF, podendo ser feitos através de Centros de Atenção Psicossocial (CAPS). Ressaltamos a importância de novas pesquisas relacionadas ao tema, pois quando feito o levantamento de artigos, foi notório a dificuldade na busca de artigos relacionadas ao tema.

\section{Referências}

Aguirre, M., Araujo, M. V., Castro, A., Trujillo, L. F., \& Sua, L. F. (2020). Importancia De La Detección Temprana De Hemoglobinopatias En La Población Pediátrica En Países En Desarrollo. Revista Chilena Pediatria. 91, 568-572.

Biomedicina Padrão: Alterações Morfológicas Das Hemácias. Https://Www.Biomedicinapadrao.Com.Br/2012/01/Alteracao-Morfologica-Das-Hemacias.Html. Brasil, Ministério Da Saúde. Secretária De Vigilância Em Saúde (2015). Doença Falciforme: Conhecer Para Cuidar.

Brasil, Ministério Da Saúde, Secretária De Atenção Á Saúde (2015). Doença Falciforme: Diretrizes Básicas Da Linha De Cuidado. Brasília. 
Brasil, Portaria N 1.321, De 21 De Dezembro De 2015. Https://Www.Brasilsus.Com.Br.

Brasil, Ministério Da Saúde, Portaria Nº 822, De 06 De Junho De 2001.

Bessoni, T., \& Federige, M. A. F. Anemia Falciforme: Um Problema De Saúde Pública, O Papel Da Triagem Neonatal No Diagnóstico E O Acompanhamento Terapêutico. Atas De Ciências Da Saúde, 2

Botler, J., Camacho, L. A. B., \& Cruz, M. M. (2013). Avaliação Das Unidades De Coleta Do Programa De Triagem Neonatal No Estado Do Rio De Janeiro. Revista Brasileira Saúde Materno Infantil, 12

Bruzeguini, V. M. (2018). Doença Falciforme E O Teste Do Pezinho: Implicações Para A Saúde Pública. Revista Brasileira De Pesquisa Em Saúde, Vitória.

Bruniera, P. (2007). Crise De Sequestro Esplênico Na Doença Falciforme. Revista Brasileira De Hematologia E Hemoterapia, $29,259-261$.

Cavalcanti, J. M., \& Maio, M. C. (2011). Entre Negros E Miscigenados: A Anemia E O Traço Falciforme No Brasil Nas Décadas De 1930 E1940. História, Ciência, Saúde-Manguinhos, 18

Camargo, C. C. Fernandes, G. M. A. \& Chiepe, K. C. M. B. (2020). Diseases Indentified In Extended Neonatal Screening . Brazilian Jornal Of Health Review, 2019

Conran, N., \& Belcher, J. (2019) D.Inflammation In Sickle Cell Disease. The New England Journal Of Medicine, 2-3, 263-299, 20.

Crespo, M. S., Triquero, Y. H., Rodríguez, D. L. O, \& Niurka C. (2016). Programa De Prevención De Anemias Por Hematíes Falciformes: Estratégia Preventiva. Revista Ciencias Médicas De Pínar Del Rio, 24.

De Oliveira, P. K., Figueiredo, J. T. R., Vargas, I. C., Souza, L. S. M., Toledo, L. G. S., \& Paludo, R. L. R. (2020). A Importância Da Triagem Neonatal Para Diagnóstico Da Anemia Falciforme No Brasil.

De Souza, I. M., \& De Araújo, E. M. (2016). Doença Falciforme E Triagem Neonatal: Um Debate Necessário. Revista De Saúde Coletiva Da Uefs, 5, 59-61.

Diniz, D., \& Guedes, C. (2010). Informação Genética Na Mídia Impressa: A Anemia Falciforme Em Questão.

Di Nuzzo, D. V. P. \& Fonseca, S. F. (2004) Anemia Falciforme E Infecções. Jornal De Pediatria.

Fernandes, A. P. P. C., Januário, J. N., Cangussu, C. B., Macedo, D. L, \& Viana, M. B. (2010). Mortalidade De Crianças Com Doença Falciforme: Um Estudo De Base Populacional. Jornal De Pediatria, 86, 1-6.

Felix, A. A., Souza, H., \& Ribeiro, S. B. (2010) Aspectos Epidemiológicos E Sociais Da Doença Falciforme. Revista Brasileira De Hematologia E Hemoterapia, 32, 203-208.

Figueiredo, A. B., Vieira, S., F., Soares E Sá, L., \& Lopes De Sousa, N. (2014). Anemia Falciforme: Abordagem Diagnóstica Laboratorial. Revista De Ciências Da Saúde Nova Esperança, 12, 98 - 105

Frédéric B. P., Martin H. S. M. D., \& David C. R. (2017). Sickle Cell Disease. The New England Journal Of Medicine.4, 111-116

Glaustone, A. (2015). Anemia Falciforme. Campina Grande-Pb. <Http://Glaustoneagra.Blogspot.Com.Br/2015/10/Anemia-Falciforme.> .

Governo Do Brasil. O Teste Do Pezinho Será Ampliado E Detectará Até 50 Novas Doenças. Disponível Em: Https://Www.Gov.Br/Pt-Br/Noticias/Saude-EVigilancia-Sanitaria/2021/05/Teste-Do-Pezinho-Sera-Ampliado-E-Detectara-Ate-50-Novas-Doencas.

Jesus, J. A. (2020) Doença Falciforme No Brasil. Gazeta Médica Da Bahia, N. 3.

Leão, L. L., \& Aguiar, M. J. B. (2008) Triagem Neonatal: O Que Os Pediatras Deveriam Saber. Jornal De Pediatria. 84

Lopes, W. S., \& Gomes, R. (2020). A Participação Dos Conviventes Com A Doença Falciforme Na Atenção À Saúde: Um Estudo Bibliográfico. Ciência \& Saúde Coletiva Vol 25.

Lervolino, L. G., Baldin, P. E. A., Picado, S. M., Calil, K. B., Viel, A. A., \& Campos, L. A. F. (2011). Prevalence Of Sickle Cell Disease And Sickle Cell Trait In National Neonatal Screening Studies. Revista Brasileira De Hematologia E Hemoterapia. 33, 49-54.

Lorenzi, T. F. (2006) Manual De Hematologia: Propedêutica E Clínica. (4a ed.), Editora Guanabara Koogan.

Ima, K, T. L. L, Ferreira, P. J. O, Melo, P. R, Correia, K. A, \& Rodrigues, F. M. (2019). Qualidade De Vida Dos Portadores De Doença Falciforme. Revista De Enfermagem Ufpe.

Menezes. A. S. O.P., Len, C. A., Hilário, M. O. E., Terreri, M. T. R. A., \& Braga, J. A. P. (2013). Qualidade De Vida Em Portadores Da Doença Facilforme. Machado, P., Mendes, C., Rosário, V. E., Arez, A. P. A. (2010). Contribuição Do Polimorfismo Humanos Do Eritrócito Na Proteção Contra A Malária. Revista Pan-Amazônica De Saúde.

Maia, A. O., Gomes, K. K. A., Silva, I. R. L., \& Almeida, M. M. C. (2017). A Importância Do Diagnóstico Precoce Da Anemia Falciforme. Journal Of Medicine And Health Promotion. 670-675. 03.

Mendonça, A. C., Garcia, J. L., Almeida, C. M., Megid, Thiago B. C., \& Júnior, A. F. (2009). Muito Além Do "Teste Do Pezinho". Revista Brasileira De Hematologia E Hemoterapia, 31, P. 66. 
Research, Society and Development, v. 10, n. 8, e38110817539, 2021

(CC BY 4.0) | ISSN 2525-3409 | DOI: http://dx.doi.org/10.33448/rsd-v10i8.17539

Martins, P. R. J., Souza H. M., \& Silveira, T. B. (2010). Morbimortalidade Em Doença Falciforme. Revista Brasileira De Hematologia E Hemoterapia. Vol. 32 No. 5 São Paulo.

Nugo, D, \& Steinberg, M. (2014). Sickle Cell Disease. Hematology Clinic, 1-6, 19.

Nogueira, K. D. A., Silva, W. D. L., \& Paiva, S. G. (2013). Diagnóstico Laboratorial Da Anemia Falciforme. Revista Científica Do Itpac.

Nupad, Faculdade De Medicina Da Ufmg: Doença Falciforme. Https://Www.Nupad.Medicina.Ufmg.Br/Topicos-Em-Saude/Doenca-Falciforme/.

Piel, F.B., Steinberg, M. H., \& Rees, D. C. (2017). Sickle Cell Disease. New England Journal Of Medicine: Review Article. P. 1561-1573.

Rodrigues, D. O. W., Ferreira, M. C. B., Campos, E. M. S., Pereira P. M., Oliveira, C. M., \& Teixeira M. T. (2010). Diagnóstico Histórico Da Triagem Neonatal Para Doença Falciforme. Rev. Aps, 13, 34-45.

Rodrigues, D. O. W., Ferreira, M. C. B., Campos, E. M. S., Pereira P. M., Oliveira C. M., \& Teixeira M. T. (2012). História Da Triagem Neonatal Para Doença Falciforme No Brasil - Capítulo De Minas Gerais. Revista Médica De Minas Gerais.

Rosenfeldl, L. G. (2019). Prevalência De Hemoglobinopatias Na População Adulta Brasileira: Pesquisa Nacional De Saúde 2014 - 2015. Revista Brasileira De Epidemiologia. 22.

Reis, M. A., Silva, C. T. X., Souza, N. M. Ca., \& Silva, M. M. Teste Do Pezinho: Conhecimento Da Gestante Quanto A Sua Importância, Anápolis-Go- Brasil, 2019.

Santos, I. N., Damião, J.J., Freitas V. M., Rodrigues, C. S., \& Aguiar, O. B. (2020). Condições Clinicas, Nutricionais E Sociais De Crianças Com Doença Falciforme Acompanhadas Em Um Centro De Referencias: Estudo Descritivo, Revista Demetria Alimentação E Nutrição Em Saúde Coletiva.

Silva Rs, Borges Rc. (2019). O Papel Do Biomédico No Diagnóstico Da Anemia Falciforme. Anais Do $18^{\circ}$ Simpósio De Tcc E $15^{\circ}$ Seminário De Ic Do Centro Universitário Icesp.

Silva, N. C. H, Silva, J. C. G, Melo, M. G. N. De, \& Souza, I. F. A. C. (2017). Principais Técnicas Para O Diagnóstico Da Anemia Falciforme: Uma Revisão De Literatura. Caderno De Graduação - Ciências Biológicas E Da Saúde - Unit - Pernambuco.

Souza, C. F. M., Schwartz, I. V., \& Giugliani, R. (2002). Triagem Neonatal De Distúrbios Metabólicos. Ciência E Saúde Coletiva. 7

Souza, A. P., \& Oliveira, E. F. (2017). A Importância Da Realização Precoce Do Teste Do Pezinho: O Papel Do Enfermeiro Na Orientação Da Triagem Neonatal. Revista Multidisciplinar De Psicologia. 11

Soares, L. F, Lima, E. M. Slva, J. A. Fernandes, S. S. Silva, K. M. C. Lins, S. P. Damasceno, B.P.G.L. Verde, R. M. C. \& Gonçalves, M. S. (2017). Prevalência De Hemoglobinas Variantes Em Comunidades Quilombolas No Estado Do Piauí, Brasil. Revista Ciência E Saúde Coletiva.

Zuniga, C. P., Martínez, G. C., González, R. L. M., Rendón, C. D. S., Rojas, R. N., Barriga, C. F., \& Wietstruck, P. M. A. (2018). Enfermedad De Células Falciformes: Un Diagnóstico Para Tener Presente. Revista Chilena De Pediatría, P. 1-6. 